\title{
Phonetics or Phonology: Asymmetries in Loanword Adaptations - French and German Mid Front Rounded Vowels in Japanese
}

\author{
Katrin Dohlus \\ Kobe University, Japan / Humboldt-Universität zu Berlin, Germany
}

\begin{abstract}
It is one of the most highly debated issues in loanword phonology whether loanword adaptations are phonologically or phonetically driven. This paper addresses this issue and aims at demonstrating that only the acceptance of both a phonological as well as a phonetic approximation stance can adequately account for the data found in Japanese. This point will be exemplified with the adaptation of German and French mid front rounded vowels in Japanese. It will be argued that the adaptation of German /œ/ and /ø/ as Japanese /e/ is phonologically grounded, whereas the adaptation of French /œ/ and /ø/ as Japanese /u/ is phonetically grounded. This asymmetry in the adaptation process of German and French mid front rounded vowels and further examples of loans in Japanese lead to the only conclusion that both strategies of loanword adaptation occur in languages. It will be shown that not only perception, but also the influence of orthography, of conventions and the knowledge of the source language play a role in the adaptation process.
\end{abstract}

\section{Introduction}

Japanese with its five-vowel system of short and long /i, u, e, o, a/ does not have a contrast between front unrounded and front rounded vowels - it only allows the unmarked front unrounded vowels. For that reason I investigated how Japanese adapts front rounded vowels in loanwords from French and German.

Whereas the high front rounded vowels are adapted as /ju/ in loanwords from German as well as from French (Dohlus 2004, 2005), the mid front rounded vowels reveal an interesting asymmetry in Japanese: German /œ/ and $/ \varnothing /$ are adapted as Japanese /e/, but French /œ/ and /ø/ are adapted as Japanese $/ \mathrm{u} /$. 
The first thing that comes to mind is that the different adaptation forms in Japanese are caused by differences between the German and French mid front rounded vowels. However, a comparison between both source vowels refutes this assumption.

Phonologically, German and French /œ/ and /ø/ are identical. In both languages these sounds carry the combination of the phonological features [-high], [coronal], [labial], and [lax] or [tense], respectively ${ }^{1}$. A comparison of acoustic features also shows a high similarity between German and French /œ/ as well as /ø/. Delattre (1965) for instance gives identical F1 and F2 values for the tense vowels (F1: $375 \mathrm{~Hz}, \mathrm{~F} 2: 1600 \mathrm{~Hz}$ ) and similar values for the lax vowels (German [œ] F1: 500 Hz, F2: 1550 Hz, French [œ] F1: 550 Hz, F2: 1400 $\mathrm{Hz}$ ). There are of course differences between German and French in a broader context, for instance in the vowel inventory and in terms of stress or rhythm. However, we will see in the paper that German and French mid front rounded vowels are similarly perceived as / $\mathrm{u} /$ by speakers of Japanese. Instead of being caused by differences between the German and French source vowels, I will argue that the asymmetry in the adaptation forms is grounded on the application of different adaptation strategies: The adaptation of German mid front rounded vowels as /e/ in Japanese is an example of phonological approximation, whereas the adaptation of French mid front rounded vowels as $/ \mathrm{u} /$ is an example of phonetic approximation.

\section{Approaches to Loanword Phonology}

Before discussing the problem of the asymmetry in the adaptation patterns of German and French mid front rounded vowels in Japanese, I want to give a short overview of different approaches to loanword adaptation. The current literature distinguishes two main positions - the phonological and the phonetic approximation stance.

\subsection{Phonological Approximation Stance}

LaCharité \& Paradis (2005: 223) argue "that loanword adaptation is overwhelmingly phonological” (see also Paradis \& LaCharité 1997, Danesi 1985, Lovins 1975). Their major claim is that loanword adaptation is based on the identification of phoneme categories of the source language and that phonetic approximation plays only a minor role. This presupposes that

1 For a detailed definition of the features [coronal] ("involving a constriction formed by the front of the tongue") and [labial] ("involving a constriction formed by the lower lip") see Clements and Hume (1995). 
borrowers are bilingual and have an extended knowledge of the source language (LaCharité \& Paradis 2005). Borrowers correctly perceive the phonological categories of the source language, they "accurately identify L2 [source language] sound categories; that is, they operate on the mental representation of an L2 sound, not directly on its surface phonetic form" (LaCharité \& Paradis 2005: 223, see also Jacobs \& Gussenhoven 2000). Hence, according to the phonological approximation stance, perception of foreign sounds is faithful and sounds are only altered in production, where the phonological contrasts of the source language are preserved to the greatest extent possible.

The following examples, taken from LaCharité \& Paradis (2005) support the phonological approximation stance.

(1) Examples of phonological approximation ${ }^{2}$

(1a) English voiced stops in Spanish:

A comparison of VOT indicates that Spanish voiceless sounds overlap with English voiced sounds (both have a VOT of 0-30 msecs). This is underlined by the misperception of English voiced sounds as voiceless by Spanish learners of English. However, English loanwords with voiced stops are not adapted as voiceless in Spanish, but as the phonologically identical category [voiced] (LaCharité \& Paradis 2005). Similarly, English /b/ is adapted as /b/ in French despite being acoustically closer to French /p/ (LaCharité \& Paradis 2005).

(1b) English high lax vowels in Spanish:

English [I] and [U] are phonetically closest to the Spanish phonemes /e/ and /o/. Despite this phonetic closeness, English [I] and [u] are adapted as /i/ and $/ \mathrm{u} /$ in Spanish, because they are phonologically identical to the phoneme category of the English source vowels (LaCharité \& Paradis 2005).

(1c) English [0] in Italian Calabrese:

English $[\theta]$ is perceptually closest to Calabrese Italian /f/, but it is adapted as /f/ in only a minority of adaptations (2/64 words). In the majority of cases, /t/ is chosen for the representation of English [ $\theta$ ] in Calabrese Italian (62/64 words) (LaCharité \& Paradis 2005).

2 The adaptation forms in the following examples appear to be caused by the influence of orthography. However, LaCharité \& Paradis (2005: 237) state that orthography plays only a limited role in their database: "Despite what is often believed, the clear influence of orthography is generally weak". I will discuss the influence of orthography in section 4.4. 
These examples show that despite the existence of a phonetically identical or closer sound, the phonologically identical sound of the borrowing language is chosen. They thus indicate that the adaptations are phonologically driven and that "phonetic approximation cannot be held responsible for the adaptation" (LaCharité \& Paradis 2005: 235). Foreign sounds are adapted as native sounds that preserve the phonological contrasts of the source language to the greatest extent possible.

\subsection{Phonetic Approximation Stance}

Peperkamp \& Dupoux (2003), Vendelin \& Peperkamp (2004), Kenstowicz (2005) and others hold the opposite standpoint, namely that adaptation is solely determined by acoustic and perceptual factors. Peperkamp \& Dupoux (2003: 368) propose "that indeed all adaptations apply in perception and that they are always phonetic in nature". Adaptation is driven purely by auditory perception, and "a given input sound will be mapped onto the closest available phonetic category” (Peperkamp \& Dupoux 2003: 368). 'Available phonetic category' hereby indicates that the perception and categorisation of foreign sounds is language-specific: "With respect to nonnative sounds, this mapping is of course massively unfaithful, since the phonetic categories to which these sounds are mapped in the foreign language can simply be absent from the native one" (Peperkamp \& Dupoux 2003: 368). Phonological features of a sound in the source language do not play any role and may not even be known to the borrower.

That adaptation is driven phonetically is shown by examples in which 1) a foreign sound is adapted as the phonetically closest native sound irrelevant of the existence of a sound that is identical or closer to the source phoneme in phonological terms, and 2) phonologically identical sounds are adapted differently in a given language because of minimal phonetic differences. The following examples are taken from Vendelin \& Peperkamp (2004).

(2) Examples of phonetic approximation

(2a) English /v/ in Cantonese:

Cantonese does not have the voiced fricative $/ \mathrm{v} /$, only its voiceless counterpart /f/. However, English /v/ is not adapted as the phonologically closest phoneme /f/, but as the acoustically most similar Cantonese /w/.

(2b) Adaptation of English and French /n/ into Japanese

English and French word-final $/ \mathrm{n} /$ are adapted differently in Japanese, English /n/ as the Japanese moraic nasal /n/, French /n/ as a nasal geminate 
followed by an epenthetic vowel, -nnu. This, Vendelin \& Peperkamp (2004) argue, is due to the phonetic differences between English /n/ (no release) and French /n/ (release and longer duration) which are perceived by Japanese listeners.

These examples demonstrate "that loanword adaptations are not due to the phonological grammar, but rather to perceptual processes involved in the decoding of nonnative sounds" (Peperkamp \& Dupoux 2003: 367).

This section showed that there are two approaches to loanword adaptation. In the following section I will analyse the data from Japanese in phonological as well as phonetic terms and argue that German /œ/ and /ø/ are adapted on phonological grounds, but French /œ/ and /ø/ on phonetic grounds.

\section{The Asymmetry in the Adaptation of German and French / /e/ and /ø/ in Japanese}

\subsection{German /oe/ and /ø/ in Japanese}

As the examples in (3) illustrate, German /œ/ and /ø/ are adapted as /e/ in Japanese (for sources see Appendix Sources of loanword data).

(3) Adaptation of German /œ/ and /ø/ $\rightarrow$ Japanese /e/ (41/41 words) ${ }^{3}$

\begin{tabular}{|c|c|c|c|}
\hline ökumene & [œku'me:nə] & $\rightarrow$ e $k$ kumêne & 'area of settlement' \\
\hline Röntgen & ['rœntgən] & rentogen & 'X-ray' \\
\hline othe & ['gø:tə] & gệte & Goethe (personal name) \\
\hline Schrö̈der & ['Srø:de] & $\rightarrow$ shurêêâ & Schröder (personal name) \\
\hline
\end{tabular}

3 Transcription of the Japanese data follows the Hepburn system. Vowels are pronounced as in Italian or German. Consonants are pronounced as in English $(<\mathrm{g}>$ is always pronounced as [g]). Please note particularly the following conventions:

- macrons mark long vowels

- $\quad<y>$ is pronounced as the front glide [j]

- double consonants are geminates, e.g. $<\mathrm{kk}>$ is pronounced as [k:].

As the examples in (3) show, vowel epenthesis is very common in loanwords in Japanese. With the exception of the moraic nasal and geminated consonants, consonant clusters and final consonants are disallowed in Japanese. In order to avoid consonant clusters and final consonants a vowel is inserted in Japanese. This epenthetic vowel is usually the defaultvowel /u/ (e.g. Schröder $\rightarrow$ shurêdâ). If /t/ or /d/ precedes /u/, the quality of the consonant is altered (/t/ $+/ \mathrm{u} / \rightarrow$ [tsu], $/ \mathrm{d} /+/ \mathrm{u} / \rightarrow[(\mathrm{d}) \mathrm{zu}])$, therefore, $/ \mathrm{o} /$ is inserted after $/ \mathrm{t} /$ and $/ \mathrm{d} /$, as in the example Röntgen $\rightarrow$ rentogen (for more details on vowel epenthesis in loanwords in Japanese see Lovins 1973). 


\subsubsection{Phonological Analysis of German /oe/ and /ø/ $\rightarrow$ Japanese /e/}

As can be seen in (3), German /œ/ and /ø/ are delabialised and adapted as the front unrounded vowel /e/ in Japanese. The adapted vowel maintains the features [-high] and [coronal], but loses the feature [labial] of the source vowel. The loss of [labial] is less crucial, because lip rounding and labiality play only a minor role in Japanese (Dohlus 2004) and are redundant in the description of the Japanese 5-vowel system. A comparison of the phonological features of input and output is presented in (4).

(4) Comparison of input and output features

$\begin{array}{ccl}\text { Input German /œ/ and /ø/ } & \rightarrow & \text { Output Japanese /e/ } \\ \text { [-high] } & \checkmark & \text { [-high] } \\ \text { [coronal] } & \checkmark & \text { [coronal] } \\ \text { [labial] } & : & \end{array}$

Here we see clearly that the distinctive features for vowel height and frontness are preserved, thus the phonological features of the source language are preserved to the greatest extend possible. The adaptation of German /œ/ and /ø/ as /e/ in Japanese is therefore a phonologically grounded adaptation. ${ }^{4}$

\subsubsection{Phonetic Analysis of German /o// and /ø/ $\rightarrow$ Japanese /e/}

In order to see whether the adaptation of German /œ/ and /ø/ as /u/ in Japanese is based on perception, an experiment was performed with the aim to find out as which Japanese vowel Japanese listeners perceive German mid front rounded vowels. /CVn/ syllables with varying onsets were used as stimuli, and the perception of lax [œ] as well as tense [ø:] were tested in two conditions, in citation form and in sentence condition. I asked my subjects (24 students from Kansai area) to write down in the Japanese syllabary what they heard (for details on the experiment see Dohlus 2005). The results, summarized in the following table, show that German /œ/ and /ø/ are overwhelmingly perceived as /u/ by Japanese speakers.

$4 \quad$ LaCharite \& Paradis (2005: 226) measure phonological closeness by the number of steps which have to be taken in order to make the sound permissible in the borrowing language. In the framework of Optimality Theory, phonological closeness is determined by the ranking of faithfulness constraints (see Dohlus 2004 for a phonological analysis of the adaptation of front rounded vowels into Japanese). 
Table 1: Perception of German [œ] and [ø:] by Japanese speakers

\begin{tabular}{|l|c|c|c|c|c|c||}
\hline \hline German [œ] and [ø:] & $/ \mathrm{e} /$ & /u/ & /a/ & Others & Total \\
\hline \hline \multirow{2}{*}{$\begin{array}{l}\text { Citation Form } \\
\text { Condition }\end{array}$} & {$[œ]$} & $2.0 \%$ & $\mathbf{7 4 . 8 \%}$ & $20.2 \%$ & $3.0 \%$ & $100 \%$ \\
\cline { 2 - 7 } Sentence & {$[\varnothing:]$} & - & $\mathbf{9 8 . 6 \%}$ & $1.0 \%$ & $0.4 \%$ & $100 \%$ \\
\hline Condition & {$[œ]$} & $2.0 \%$ & $\mathbf{7 4 . 8 \%}$ & $20.2 \%$ & $3.0 \%$ & $100 \%$ \\
\cline { 2 - 7 } & {$[\varnothing:]$} & - & $\mathbf{9 3 . 4 \%}$ & - & $6.6 \%$ & $100 \%$ \\
\hline
\end{tabular}

These results are not consistent with the adaptation pattern of German mid front rounded vowels as Japanese /e/, as we find it in established loans. Thus, perception cannot account for the adaptation form of German /œ/ and /ø/ in Japanese. In order to make the results easier to understand I am going to describe the characteristics of Japanese /u/ briefly.

\subsection{Characteristics of Japanese / $\mathrm{u} /$ and the Issue of Perceptual Similarity}

Phonologically, Japanese / $\mathrm{u} /$ is a back rounded vowel. Several phenomena in Japanese show that Japanese /u/ behaves as a back vowel: First, /u/ can follow the palatal glide, which only precedes back vowels (Kubozono 2002: 81), second, /u/ patterns as a back vowel in vowel coalescence (Kubozono 1999: 102), and third, $/ \mathrm{u} /$ takes the velar glide as the homorganic glide to break hiatus (Kubozono 2002: 84). As Japanese does not contrast back rounded and unrounded vowels, we can assume that Japanese $/ \mathrm{u} /$ is the universally unmarked rounded vowel (Calabrese 1995: 383, Kubozono 1999: 21ff.).

However, phonetically Japanese $/ \mathrm{u} /$ is fairly fronted and therefore a rather centralised vowel (Honma 1985: 103, Kubozono 1999: 36f.). This fronting of Japanese /u/ further results in a weakening of its lip rounding (Kubozono 1999: 37). The following chart, comparing German and Japanese vowels in terms of their first and second formants, illustrates the fronting of Japanese $/ \mathrm{u} /$.

Figure 1 shows that the phonetically centralised Japanese $/ \mathrm{u} /$ is fairly close to German front rounded vowels in terms of F2. However, perceptual similarity cannot be measured reliably by acoustic features alone. This can be seen in Figure 1 above, where acoustic similarity to German mid front rounded vowels can be stated for Japanese /u/ as well as for Japanese /e/. It cannot explain why Japanese mainly perceive /u/, but hardly ever /e/ in the case of German mid front rounded vowels. This shows that it is not acoustic features alone, but the weighting of several acoustic cues that determines perception. Studies have shown (e.g. Rochet 1995, Escudero \& Boersma 2004) that speakers of different languages or dialects identify vowels with identical formant frequency values differently. This demonstrates that perception is highly language-dependent: 
"Crosslinguistically, the attention paid to the cues that signal a contrast varies between adult speakers of different languages" (Escudero \& Boersma 2004: $552)$.

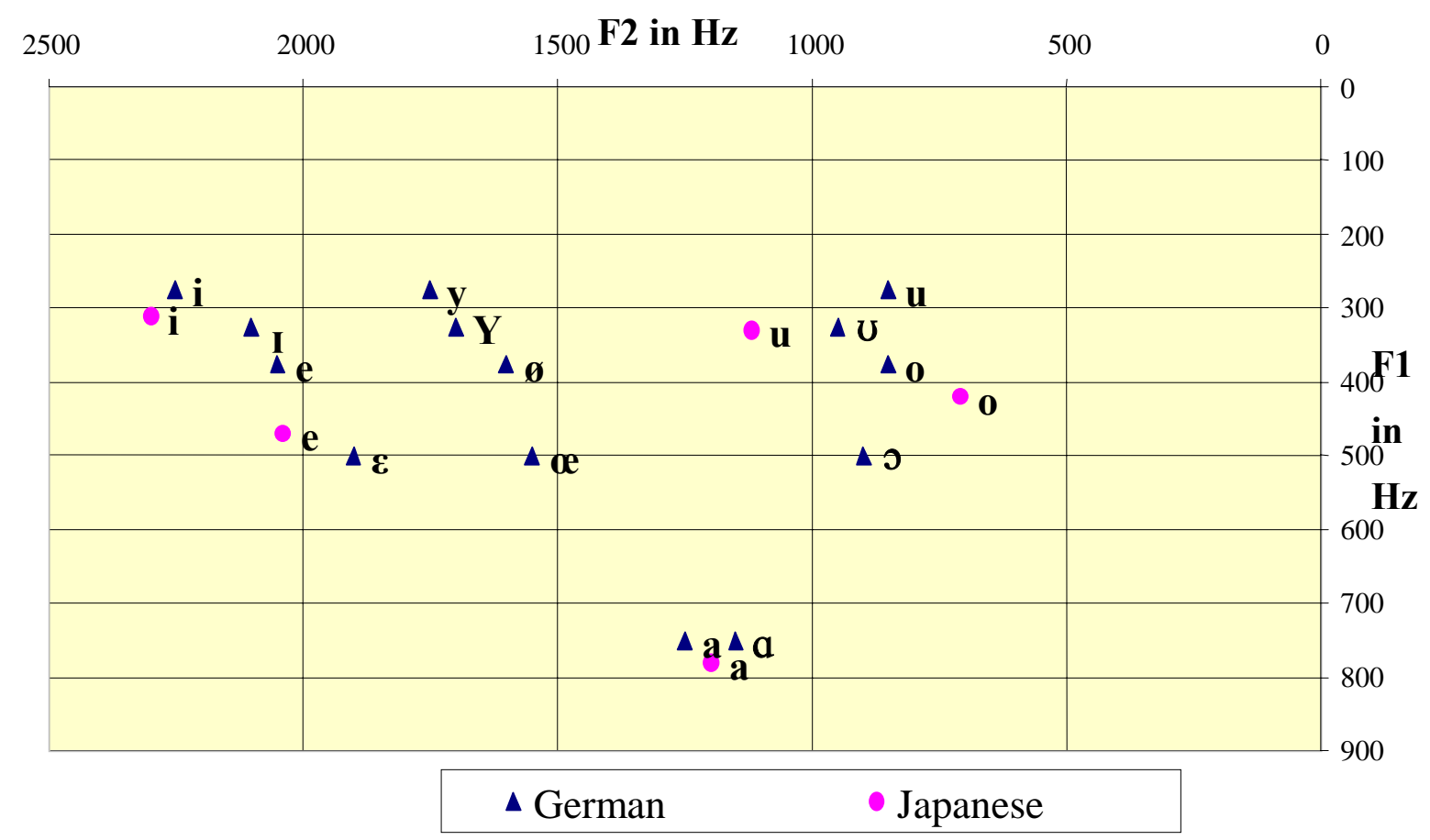

Figure 1: Formant Frequencies of German and Japanese vowels (utterances of male speakers), from: Delattre 1965 (German) and Imaishi 1997 (Japanese)

The chart above only reflects acoustic features, but not their cue-weighting in Japanese. Thus, it is a task for further research to explore experimentally which cues Japanese speakers use to which extent, and how, based on this cueweighting, they divide their perceptual vowel space. It can be expected that Japanese /u/ perceptually overlaps with the mid (and high) front rounded vowels. A good example of such a study is Rochet (1995), who investigated the asymmetry in the perception and adaptation of French /y/ in Portuguese and American English. Portuguese speakers replace /y/ by /i/, whereas American English speakers replace it by $/ \mathrm{u} /$. Rochet's experiment shows that the difference in the perception of French /y/ by speakers of Portuguese and of American English is based on "how these subjects perceive and categorize the high vowel continuum in their respective languages" (Rochet 1995: 385). In the case of Portuguese, French /y/ falls into the perceptual space of the /i/ category, whereas it falls into the /u/ category for American English speakers.

To conclude, the results of the perceptual experiment have shown that the adaptation of German /œ/ and /ø/ as /e/ in Japanese is not based on perception and thus not phonetically, but phonologically grounded. 


\subsection{French /oe/ and /ø/ in Japanese}

As the examples in (5) demonstrate, French /œ/ and /ø/ are adapted as /u/ in Japanese.

(5) French /œ/ and /ø/ $\rightarrow / \mathrm{u} /\left(13 / 17\right.$ words) ${ }^{5}$

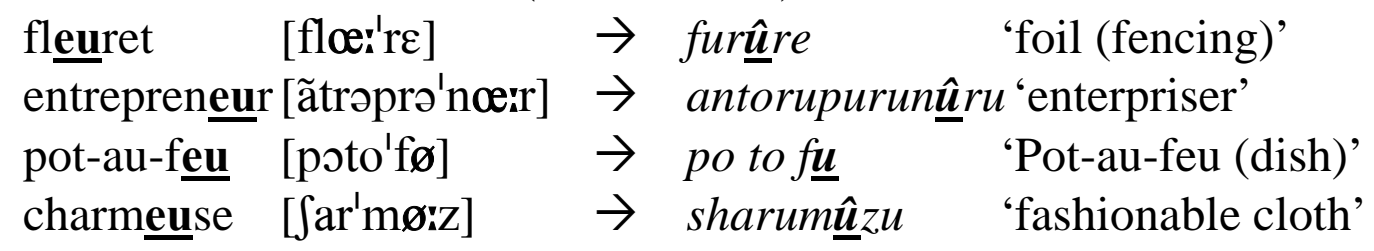

\subsubsection{Phonological Analysis of French /oe/ and /ø/ $\rightarrow$ Japanese /e/}

The French mid front rounded vowels are assimilated as high back vowels in Japanese. In (6) we see that only the feature [labial] - redundant in Japanese - is preserved, but the features [-high] and [coronal] of the French input are lost. Therefore, the adaptation of French /œ/ and /ø/ as /u/ in Japanese is not a phonologically grounded adaptation.

(6) Comparison of input and output features

Input French /œ/ and /ø/ $\rightarrow$ Output Japanese /u/

$\begin{array}{lll}\text { [-high] } & \otimes & \text { [+high] } \\ \text { [coronal] } & : & \text { [dorsal] } \\ \text { [labial] } & \checkmark & \text { [labial] }\end{array}$

\subsubsection{Phonetic Analysis of French /oe/ and /ø/ $\rightarrow$ Japanese /e/}

As the perceptual experiment described above has shown, Japanese /u/ appears to be the sound that is perceptually closest to German /œ/ and /ø/. The same results could be expected for French /œ/ and /ø/. Indeed, Shinohara (1997), who asked her Japanese subjects to convert French words into Japanese, showed that French $/ œ /$ and $/ \varnothing /$ are perceptually closest to Japanese $/ \mathrm{u} /$. All of her three

5 The other four words containing /œ/ or /ø/ in French are adapted as follows: 1) /œ/ $\rightarrow$ /o/ (hors-d'œuvre [or'dœivrə] $\rightarrow$ ôdoburu 'side-dish', 2) /œj/ $\rightarrow$ /îju/ cerfeuil [scr'fœj] $\rightarrow$ serufiiyu 'chervil', millefeuille [mil'foj] $\rightarrow$ mirufiiyu 'pie-like cake', and 3) /jø/ $\rightarrow$ /iju/ faux camaïeu [fokama'jø] $\rightarrow$ fô kamaiyu 'colourless'.

Note that nasalised vowels are adapted as a sequence of oral vowel and nasal consonant $(/ \mathrm{Vn} /)$. On epenthetic vowels see footnote 3 in section 3.1. 
subjects represented the French vowel as /u/ (16/16 words, in a few cases /o/ or

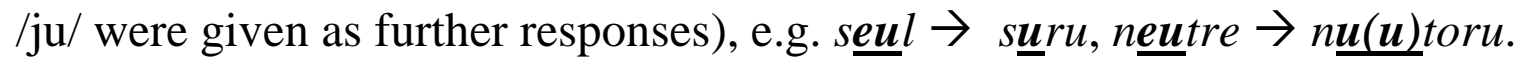

\section{$\mathrm{F} 2$ in $\mathrm{Hz}$}

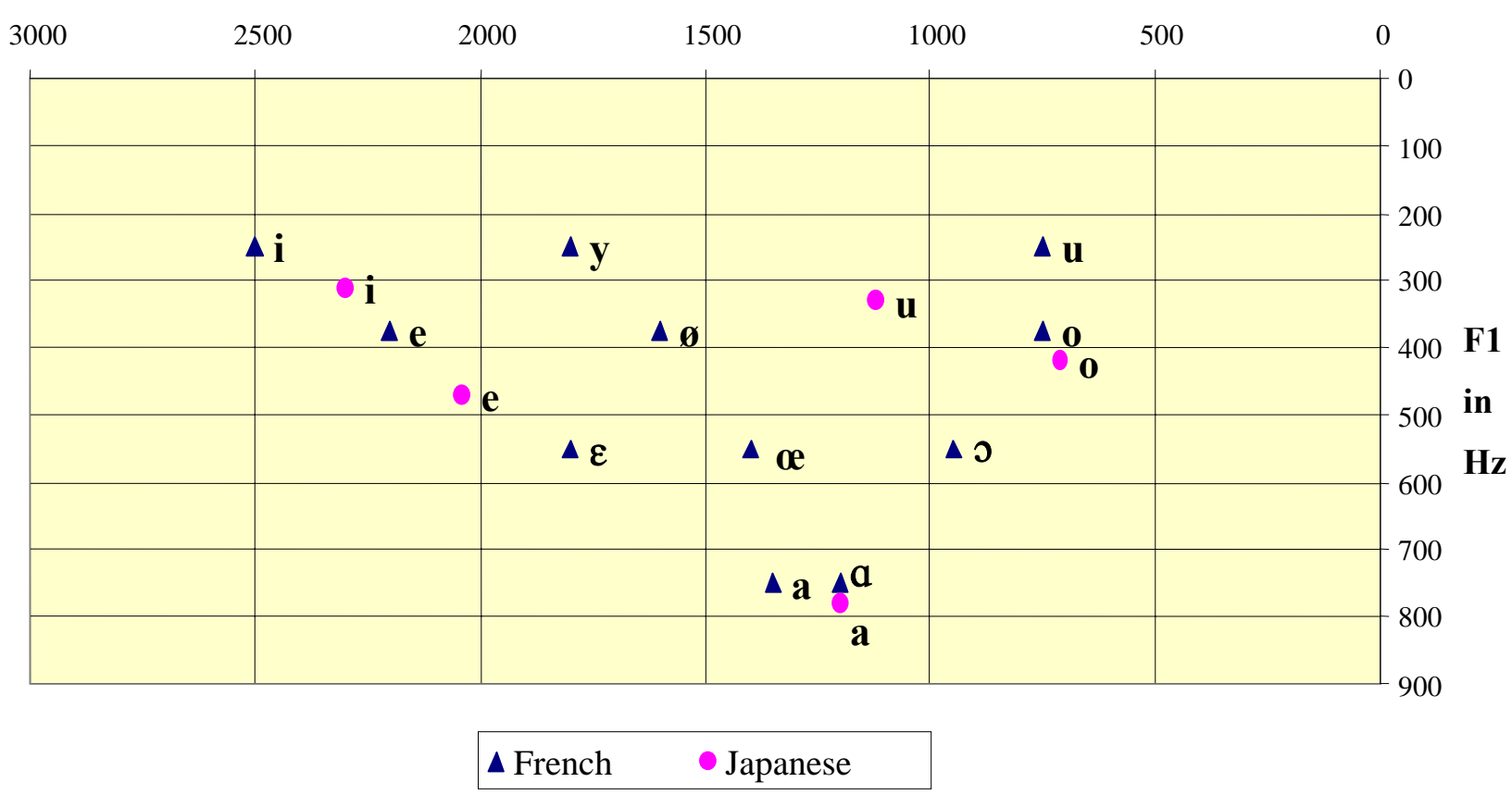

Figure 2: Formant Frequencies of French and Japanese vowels (utterances of male speakers), from: Delattre 1965 (French) and Imaishi 1997 (Japanese)

In figure 2, which compares French and Japanese vowels in terms of F1 and F2, we find a plausible explanation for the perception of French mid front rounded vowels as /u/ in Japanese, namely the high F2 values of Japanese /u/. However, as said before (see section 3.2), formant frequency values alone cannot account for perceptual similarity, because language-specific weighting of several acoustic cues determines perception.

\section{Phonetically or Phonologically Grounded Adaptation?}

The asymmetry in the adaptation patterns of German and French mid front rounded vowels in Japanese shows that we find different adaptation strategies in Japanese.

German /œ/ and /ø/ $\rightarrow$ Japanese /e/ is a phonologically driven adaptation. The phoneme categories of the sound in the source language are - irrelevant of phonetic characteristics - maintained to the greatest extent possible in Japanese.

In contrast, the pattern of French /œ/ and /ø/ $\rightarrow$ Japanese /u/ constitutes an example of phonetic approximation. The phonological features that the sound carries in the source language are irrelevant, the features [-high] and [coronal] of 
the input vowels are lost. Rather, acoustic features and perceptual similarity determine the output form. As seen above, Japanese / $\mathrm{u} /$ appears to be the sound that Japanese listeners perceive when hearing mid front rounded vowels.

In order to understand the asymmetry better, I investigated further examples of phonetically or phonologically driven adaptations. As this section will show, data from Japanese offer further examples for both adaptation strategies.

\subsection{Further Examples of Phonetic Approximation}

In Japanese, we find a number of further examples of phonetic approximation, see for instance (7) and (8).

(7) Word-final /n/ in Japanese

(7a) English $/ \mathrm{n} /$ (no release) $\rightarrow$ Japanese $/ \mathrm{n} /$ cotton ['kptn] $\rightarrow$ kotton 'cotton' line $\quad$ [lain] $\rightarrow$ rain

(7b) French /n/ (release and longer duration) $\rightarrow$ Japanese $n n u$ (geminated nasal plus epenthetic vowel)

parisienne [pari'zjen] $\rightarrow$ parijennu 'woman from Paris'

Cannes [kan] $\rightarrow$ kannu Cannes (place name)

The minimal differences in the source languages, namely that French word-final $/ \mathrm{n} /$ is, in contrast to English word-final /n/, characterised by a release and longer duration, are perceived by speakers of Japanese and reflected in the adaptation forms. These phonetic details are perceived, because Japanese differentiates the single nasal $/ \mathrm{n} /$ and the geminated nasal followed by an epenthetic vowel in its vocabulary.

A second example is the adaptation of the English low front vowel /æ/. Whereas English /æ/ is usually adapted as /a/ in Japanese (see (8a)), sequences of a velar consonant and /æ/ are adapted as a sequence of velar consonant, front glide and /a/, namely kya ([kja]) and gya [gja] in Japanese (see (8b)). Whether the English vowel /æ/ is adapted as a single vowel or as a sequence of front glide and vowel in Japanese appears to depend on the absence or presence of a preceding velar consonant. 
(8) Adaptation of English /æ/ in Japanese

(8a) English /æ/ $\rightarrow$ Japanese /a/

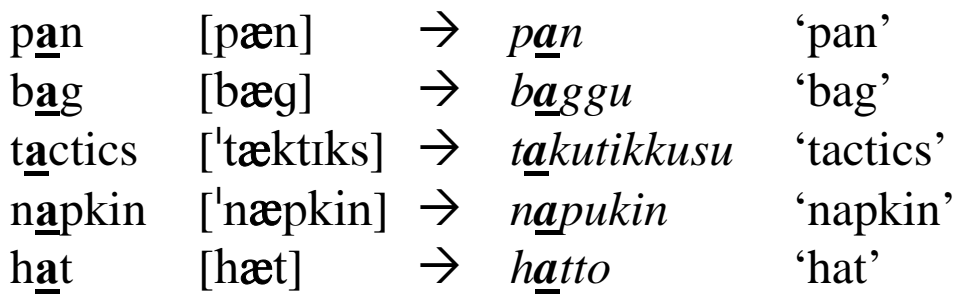

(8b) Velars preceding /æ/: English /kæ/ and /gæ/ $\rightarrow$ Japanese /kja/ and /gja/

\begin{tabular}{|c|c|c|c|c|}
\hline cat & [kæt] & $\rightarrow$ & kyatto & 'cat' \\
\hline $\mathrm{mp}$ & [kæmp] & $\rightarrow$ & kуатри & 'camp, camping' \\
\hline $\lg$ & [gæn] & $\rightarrow$ & gyangu & 'gang' \\
\hline lery & ['gæləri] & $\rightarrow$ & gya $r a r i ̂$ & 'gallery' \\
\hline
\end{tabular}

The asymmetry in the adaptation forms of (8a) and (8b) is probably caused by the phonetic differences in the pronunciation of particularly American English, where the "velar stop contact is particularly sensitive to the nature of an adjacent vowel (especially a following vowel). Thus, when a front vowel follows, e.g. /i:/ in key, geese, the contact will be made on the most forward part of the soft palate and may even overlap onto the hard palate" (Gimson \& Cruttenden 1994: 153). I assume that the fronting of the velars is perceived by speakers of Japanese and reflected in the adapted forms by the insertion of a front glide. This again is plausible because Japanese phonemically differs between syllables like $/ \mathrm{ka} /$ or $/ \mathrm{ga} /$ on the one hand and $/ \mathrm{kja} /$ or $/ \mathrm{gja} /$ on the other hand.

\subsection{Adaptation is Phonetically Driven}

The examples above support the assumption that loanword adaptation is phonetically driven and based on perception. Indeed, this is most reasonable to me. First, the opposite standpoint, namely the phonological approximation stance, assumes that the phoneme categories of the source language are correctly identified. However, a large number of studies have shown that perception of foreign sounds is not faithful, but heavily influenced by one's native language (e.g. Best \& Strange 1992, Dupoux et al. 1999, Rochet 1995). Borrowers are confronted with sounds of a foreign language, and thus their perception, I 
assume, is not faithful ${ }^{6}$. Rather, they map these sounds onto their native phonetic categories - as argued by the phonetic approximation stance.

To conclude, I argue that loanword adaptation is phonetic in nature and based on the (often unfaithful) perception of foreign sounds. However, as the adaptation of German /œ/ and /ø/ as Japanese /e/ has shown, there are examples of phonological approximation. A few more examples are presented in the next subsection.

\subsection{Further Examples of Phonological Approximation}

Further examples of phonological approximation are for instance the adaptation of syllabic /r/ (see (9)) or schwa (see (10)) in Japanese. In the case of schwa for instance, Japanese $/ \mathrm{u} /$ is the acoustically and perceptually closest sound, but German schwa is adapted as the phonologically identical /e/ in the majority of cases.

(9) German Syllabic -(e)r [e] $\rightarrow$ Japanese /eru/:

$\begin{array}{lllll}\text { Kaiser } & {[\text { 'kaize }]} & \rightarrow & \text { kaizeru } & \text { 'title of German emperor' } \\ \text { Kocher } & {[\text { 'koxe }]} & \rightarrow & \text { kohh } \underline{\underline{e r u}} & \text { 'portable cooker' }\end{array}$

(10) German schwa [ə] $\rightarrow$ German /e/ (not /u/):

$\begin{array}{lllll}\text { Abend } & \text { ['a:bənt] } & \rightarrow & \text { âbento } & \text { 'evening concert/movie' } \\ \text { Eishaken } & \text { ['aisha:kən] } \rightarrow & \text { aisuhaken } & \text { 'piton' }\end{array}$

Examples presented in (9) and (10) immediately raise the question of whether these adaptation forms are not simply orthographically-based adaptations.

I do not think that they constitute purely orthographically based adaptations, first, for the reason that the German or French writing system differs from the Japanese one, and second, for the reason that phonological similarity between input and output can be observed. However, the great influence that orthography has on adaptation cannot be denied.

6 Even if one assumes the ideal case that the borrower has close-to-native-proficiency in the source language, it does not change the situation significantly, because the borrowed form will sooner or later hit a bilingual with less proficiency or a monolingual, as also Peperkamp \& Dupoux (2003: 369, footnote 2) point out: “it might very well be the case that the bilinguals who introduce these loanwords pronounce them as in the source language and that the adaptations are subsequently done by the monolingual population”. 


\subsection{The Role of Orthography}

Vendelin \& Peperkamp (2005) demonstrate how orthography influences adaptation. In an experiment they tested the adaptation of English words by French speakers in an oral-only and an oral-written condition. The results show that subjects relied purely on perception in the oral-only condition. In the oralwritten condition though, subjects applied a grapheme-to-phoneme correspondence that they had acquired in foreign-language classes (Vendelin \& Peperkamp 2005).

This experiment points out the problem: written forms give information or hints on the phoneme in the source language. Irrespective of unfaithful perception, written forms offer the possibility to correctly identify the phoneme categories of the source language. To give a simple example: a Japanese speaker who cannot perceive the difference between English /r/ and /l/ knows with some minimal knowledge of English spelling very well whether he is confronted with $/ \mathrm{r} /$ or $/ \mathrm{l} /$.

Thus, orthography enables faithful perception due to hinting to the source phoneme and as a consequence triggers phonological approximation. Perception becomes secondary if one can reliably identify the source sounds due to the presence (or knowledge) of the source's written form.

As written forms always played a major role in Japanese - the focus of foreign-language learning has been on translations, there is little contact with native speakers in Japan, and foreign-language classes are still mainly grammar/translation oriented - it is not surprising to find a large number of examples of phonological approximation in Japanese.

\subsection{Problem of Conventions}

A second major issue in dealing with loanwords are conventions. In the case of Japanese, we still find a variety of adaptation forms for German mid front rounded vowels in the $19^{\text {th }}$ century. Yazaki (1964: 170) for instance lists 29 different adaptation forms for the name of the German author Goethe (['gø:tə]). However, with the $20^{\text {th }}$ century, adaptation forms became standardised by the publishing of loanword dictionaries, by conventions of the Kokugo Shingikai (National Language Inquiry Commission) and also by foreign-language classes.

Conventions are grapheme-to-phoneme-correspondences based on written forms and thus trigger phonological approximation. 


\subsection{Knowledge of the Source Language}

Knowledge of the source language ${ }^{7}$ provides information on the phonological contrasts of the source language. It may trigger the application of an already established adaptation pattern, as acquired in foreign-language classes. The claim that knowledge of the source language influences perception, and thus also loanword adaptation, is supported by a number of studies (e.g. LaCharité \& Paradis 2005, Silverman 1992). For instance, the perception of English rhotics by Japanese listeners differs according to the English proficiency of the Japanese: "those Japanese speakers with little or no exposure to spoken English classified the English onset rhotic on phonetic grounds, while those with more experience classified it on phonological grounds" (LaCharité \& Paradis 2005: 245). Similarly, the perception of English voiced stops in Spanish varies in dependence on their knowledge of English: "monolingual Spanish speakers classify English stops on phonetic grounds, leading to their (mis)identification as voiceless, in accordance with the VOT values of Spanish. However, as English proficiency improves, the VOT value boundary approaches that of English monolinguals, with the classification performance of Spanish-English bilinguals being comparable to that of English monolinguals" (LaCharité \& Paradis 2005: 247). Studies like these constitute clear evidence that perception and adaptation are strongly influenced by a listener's knowledge of the source language.

\subsection{Conclusion: Phonetics or Phonology}

As argued before, I assume that loanword adaptation is basically phonetically grounded: foreign sounds are mapped onto the closest phonetic categories of the borrowing language. However, for a phonetically grounded adaptation, we need sufficient oral input. If there is a lack of oral input or the possibility of 'faithful perception' due to the presence of written forms, then this triggers phonological approximation. Thus, we do find phonological approximation if there is a lack of direct contact with native speakers, a major influence of written media and conventions, and knowledge of the foreign language that is based on grammar/translation-oriented foreign-language classes. These points quite well reflect the situation we find in Japan.

7 By knowledge of the source language, I mainly mean abstract 'classroom' knowledge on the source language's phonology that is supported by knowledge on the written forms, and not proficiency to the extent that the speaker has acquired the phonetic categories of the source language. 


\section{Why Different Adaptation Strategies for German and French Mid Front Rounded Vowels?}

The section above explained why both phonetic as well as phonological approximation may occur in the borrowing process. However, it still leaves the question of why the adaptation of German and French mid front rounded vowels into Japanese differs. There are two possible explanation for this asymmetry.

\subsection{Roles of German and French Loans in Japanese}

One possible explanation for this divergence in the adaptation process is grounded on different roles that German and French loans played in Japanese.

German loans, which entered Japanese mainly from the end of the $19^{\text {th }}$ century on, are words from the fields of medicine, philosophy, chemistry, and outdoor and ski sports. Most of the German loans in Japanese are academic terms used in sciences only. This indicates that German words almost certainly reached Japan in the context of the studies of sciences, and thus mainly via written media. German was also extensively used in higher education (Loveday 1996, Kuze 1976), which was based on written materials and might have fastened the process of standardisation of the adapted forms.

In contrast, French loans, entering Japanese mainly from mid $19^{\text {th }}$ century, are words from the fields of fashion, French cuisine, arts, dancing and military (Yazaki 1964). French loans appeared to have played a great role in everydaycommunication (Steinberg 1996) and thus French most likely provided more oral input than German.

\subsection{Differences in the Spelling of German and French}

A second explanation for the asymmetry in the adaptation of German and French mid front rounded vowels in Japanese is related to the spelling systems of both source languages. German spelling quite faithfully reflects the pronunciation, from a written form the pronunciation of a word (and with it the phoneme categories of a sound) are easy to recognize. For instance, seeing the grapheme $<\ddot{0}>$ in a written form tells one even with low knowledge of German that this is the mid front rounded vowel. This might explain the high number of phonologically driven adaptation forms in the case of German.

In contrast, French spelling is rather difficult, not faithfully reflecting the pronunciation. For instance, the phonemes /œ/ and $/ \varnothing /$ are transcribed by the diagraphs <eu $>$ or $<œ u>$. One needs a higher knowledge of French than is needed in the case of German in order to identify phonemes correctly from written forms in French. 


\section{Conclusion}

This paper investigated the asymmetry in the adaptation patterns of German and French mid front rounded vowels into Japanese. It was shown that the adaptation of German /œ/ and /ø/ as Japanese /e/ is a phonological approximation, but the adaptation of French /œ/ and /ø/ as Japanese /u/ a phonetic approximation. In this context I argued that loanword adaptations are basically phonetically grounded, but that a lack of oral input and a large influence of written media trigger phonological approximation.

To conclude, I think that the process of borrowing is far too complex to be accounted for by phonetic approximation only. Although I assume adaptations to be fundamentally based on language-specific perception and thus to be phonetic in nature, secondary factors such as a borrower's knowledge of the source language, orthography and conventions trigger phonological approximation.

\section{References}

Best, C.T. \& Strange, W. (1992). Effects of phonological and phonetic factors on crosslanguage perception of approximants. Journal of Phonetics 20: 305-330.

Calabrese, A. (1995). A constraint-based theory of phonological markedness and simplification procedures. Linguistic Inquiry 26-3: 373-463.

Clements, G.N. \& Hume, E.V. (1995). The internal organization of speech sounds. In: Goldsmith, J.A. (ed.) The Handbook of Phonological Theory. Cambridge, Mass. and Oxford, UK: Blackwell, 245-306.

Danesi, M. (1985). Loanwords and phonological methodology. Toronto: Didier.

Delattre, P. (1965). Comparing the Phonetic Features of English, French, German and Spanish: An Interim Report. Heidelberg: Julius Groos.

Dohlus, K. (2004). The adaptation of German front rounded vowels into Japanese. Kobe Papers in Linguistics 2004-4, 1-19.

Dohlus, K. (2005). On the asymmetry in the adaptation pattern of German umlaut in Japanese. Journal of the Phonetic Society of Japan 2005-1: 39-49.

Dupoux, E., Kakehi, K., Hirose, Y., Pallier, C. \& Mehler, J. (1999). Epenthetic vowels in Japanese: A perceptual illusion? Journal of Experimental Psychology: Human Perception and Performance 25: 1568-1578.

Escudero, P. \& Boersma, P. (2004). Bridging the gap between L2 speech perception research and phonological theory. Studies in Second Language Education 26: 551-585. 
Gimson, A.C. \& Cruttenden, A. (1994). Gimson's Pronunciation of English. London et al.: Edward Arnold.

Honma, Y. (1985). Acoustic Phonetics in English and Japanese. Tokyo: Yamaguchi.

Imaishi, M. (1997). Nihongo onsei no jikkenteki kenkyû [Experimental Research on Japanese Phonetics]. Osaka: Izumi.

Jacobs, H. \& Gussenhoven, C. (2000). Loan phonology: perception, salience, the lexicon and optimality theory. In: Dekkers, J., van der Leeuw, F. \& van de Weijer, J.: Optimality Theory: Phonology, Syntax, and Acquisition, Oxford: Oxford University Press, 193210.

Kenstowicz, M. (2005). The phonetics and phonology of Korean loanword adaptation. To appear in: Rhee, S-J. (ed.) Proceedings of First European Conference on Korean Linguistics.

Kubozono, H. (1999). Nihongo no Onsei [The Sound System of Japanese]. Tokyo: Iwanami.

Kubozono, H. (2002). Prosodic structure of loanwords in Japanese: Syllable structure, accent and morphology. Journal of the Phonetic Society of Japan 6: 79- 97.

Kuze, Y. (1976). Gairaigo Zatsugaku Hyakka [Miscellaneous Studies on Loanwords in Japanese]. Tokyo: Shin-Jinbutsuoraisha.

LaCharité, D. \& Paradis, C. (2005). Category preservation and proximity versus phonetic approximation in loanword adaptation. Linguistic Inquiry 36-2: 223-258.

Loveday, L. J. (1996). Language Contact in Japan: A Socio-linguistic History. Oxford: Claredon Press.

Lovins, J.B. (1973). Loanwords and the phonological structure of Japanese. Unpublished PhD dissertation. Chicago Illinois: University of Chicago.

Paradis, C. \& LaCharité, D. (1997). Preservation and minimality in loanword adaptation. Journal of Linguistics 33, 379-430.

Peperkamp, Sh. \& Dupoux, E. (2003). Reinterpreting loanword adaptations: the role of perception. Proceedings of the $15^{\text {th }}$ International Congress of Phonetic Sciences, 367370 .

Rochet, B.L. (1995). Perception and production of second-language speech sounds by adults. In: Strange, W. (ed.) Speech Perception and Linguistic Experience. Timonium, MD: York Press, 379-410.

Shinohara, Sh. (1997). Analyse phonologique de l'adaption japonaise des mots étranger. PhD dissertation. Paris 3.

Silverman, D. (1992). Multiple scansions in loanword phonology: evidence from Cantonese. Phonology 9: 289-328.

Steinberg, J. D. (1996). Lexical Borrowing and Modernization in China and Japan. PhD dissertation. University of California, Los Angeles.

Vendelin, I. \& Peperkamp, Sh. (2004). Evidence for phonetic adaptation of loanwords: an experimental study. Actes des Journées d'Etudes Linguistique, 129-131. 
Vendelin, I. \& Peperkamp, Sh. (2005). The influence of orthography on loanword adaptations. Lingua (in press)

Yazaki, G. (1964). Nihon no Gairaigo [Japanese loanwords]. Tokyo: Iwanami.

\section{Appendix}

\section{Sources of loanword data}

The following dictionaries, travel guides and place-name dictionary are my main source of German and French loanwords in Japanese. As I investigated established loans in Japanese, I mainly relied on loanword dictionaries. However, data of loanwords that contain mid front rounded vowels in the source language are rare. Therefore, I also included data from travel guides, a placename dictionary and a few proper names as they appeared in the news (internet).

Arakawa, S. (1941). Gairaigojiten [Loanword dictionary]. Tokyo: Kadokawa.

Arakawa, S. (1967). Gairaigojiten [Loanword dictionary]. Tokyo: Kadokawa.

Chikyu no arukikata (1995/96). Doitsu [Germany]. Tokyo: Daiyamondo.

Chikyu no arukikata (1997/98). Furansu [France]. Tokyo: Daiyamondo.

Eriagaido (1997). Yôroppa [Europe]. Tokyo and Osaka: Shobunsha.

Sanseido (1923). Nihon Gairaigojiten [Japanese Loanword dictionary]. Toyko: Sanseido.

Sanseido (1977). Konsaisu Chimeijiten [Concise Dictionary of Place Names]. Tokyo: Sanseido.

Shogakukan (1998). Reibun de yomu katakanago no jiten: A Dictionary of loanwords. Tokyo: Shogakukan.

Umegaki, M. (1978). Gairaigojiten [Loanword dictionary]. Tokyo: Tôkyôdô. 